\title{
Estimating the Spatial Distribution of Soil Salinity with Geographically Weighted Regression Kriging and Its Relationship to Groundwater in the Western Jilin Irrigation Area, Northeast China
}

\author{
Siyu Nie ${ }^{1 *}$, Jianmin Bian ${ }^{2}$, Yanchun Zhou ${ }^{1}$ \\ ${ }^{1}$ School of Water Conservancy \& Environment Engineering, Changchun Institute of Technology, \\ Changchun, 130012, China \\ ${ }^{2}$ Key Laboratory of Groundwater Resources and Environment, Ministry of Education, Jilin University, \\ Changchun 130021, China
}

Received: 30 March 2020

Accepted: 3 May 2020

\begin{abstract}
To investigate the problem of secondary salinization in agricultural irrigated areas with shallow buried groundwater, regression Kriging (RK) and geographically weighted regression Kriging (GWRK) methods were applied using soil salinity in Da'an, western Jilin province, China. Digital elevation model (DEM), Topographic Wetness Index (TWI) and Groundwater salinity were selected as auxiliary variables based on correlation analysis and stepwise regression analysis. Results showed that the RK and GWRK can both effectively predict the spatial distribution of soil salinity due to the incorporation of auxiliary variables. In addition, the GWRK accuracy is improved by $23.2 \%$, which should be attributed to the consideration of sample spatial non-stationarity. According to qualitative relationship of soil salinity and groundwater, when the groundwater depth was less than $5 \mathrm{~m}$ with the similar groundwater salinity, the soil salinity increased with decreasing groundwater depth, while more than $5 \mathrm{~m}$ the soil salinity remain unchanged. The relationship between soil salinity, groundwater depth and salinity could be quantitatively expressed using multiple power functions through data fitting. The results provide a scientific basis for regulating groundwater to control soil salinity to prevent soil salinization, and quantitative analysis needs further research.
\end{abstract}

Keywords: soil salinity, distribution characteristics; GWRK, groundwater

*e-mail: nsy727@126.com 


\section{Introduction}

Soil salinization, which is one of the main forms of soil degradation, usually occurs in areas with an arid climate, strong soil evaporation capacity and shallow groundwater, and is mainly influenced by natural factors such as climate, geology, soil texture and human activities [1-3]. Controlling and evaluating the spatial and temporal distribution of soil salinization is important in many fields. Hence methods producing reliable maps of soil salinity are necessary.

The main methods for obtaining soil salinization data include field sampling. It has large uncertainties, because of data density and soil variability, which could lead to significant errors in salinization distribution prediction. It is influenced by regional topography and land, and is closely related to many natural geographical factors, such as elevation, slope, aspect, water environment etc.. Geostatistics is the most widely used method to investigate these characteristics [4]. Because of limitations of the interpolation methods, scholars have incorporated environmental variables into the interpolation model to estimate the principal variables, such as cokriging, geographically weighted regression (GWR), artificial neural networks (ANN), regression Kriging (RK), Bayesian maximum entropy (BME) interpolation [5-7]. $\mathrm{RK}$ is a spatial prediction technique, which is combined with a regression forecast of auxiliary variables and Kriging interpolation of the regression residuals [8]. But soil is a highly variable continuum, the global model of the ordinary least square (OLS) method cannot capture the local characteristics of soil variation, thus introducing the GWR. Geographically weighted regression Kriging (GWRK) is a combination of GWR and Kriging method. The regression process of GWRK conforms to the local trend around the prediction point. The nonstationary relationship between spatial variables can be adapted. Better explain the change of target variable in space [9]. It has been widely used in earth science, especially in the study of spatial distribution of soil properties [7, 10-13]. Numerous environmental variables have been employed to map soil attributes; however, spatial distribution of soil salinity using GWRK relatively rarely reported in literatures, so its accuracy needs to be further studied.

The western of Jilin in northern China is an agricultural irrigation area, among which Da'an city has the highest degree of soil salinization [14]. To improve salinized soil, water is controlled and salinity is regulated through water diversion projects. Soil salinity fluctuates seasonally due to irrigation and drainage [15]. Surface water increased and underlying surface conditions changed, which make groundwater depth and water chemistry has changed. The water and salinity of soil is directly affected according to the hydraulic relationship between groundwater and soil water, which may lead to secondary salinization of soil $[16,17]$. Most qualitative and quantitative analyses have investigated between soil salinity and groundwater depth and concentrated in the Yellow River Delta, Hetao irrigation area, and arid areas such as northwest Xinjiang [3, 18, $19]$, in this region are rare.

Based on the above characteristics, this study assess the performance of RK and GWRK in the soil salinity interpolation processes to investigate the spatial variation characteristics. Then, quantitative analysis the relationship between soil salinity, groundwater depth and salinity, exploring the empirical formula to control soil salinity by groundwater regulated in Da'an, western Jilin, China. It provides scientific basis for irrigation and drainage system to effectively prevent soil secondary salinization.

\section{Material and Methods}

\section{Study Area}

Da'an in western Jilin has a total area of $4924 \mathrm{~km}^{2}$ $\left(123^{\circ} 08^{\prime}-124^{\circ} 21^{\prime} \mathrm{E}, 44^{\circ} 57^{\prime}-45^{\circ} 45^{\prime} \mathrm{N}\right)$. The landform is flat and open, showing higher eastern and western regions and less relief (Fig. 1). Climate change are obvious, with precipitation occurring in low amounts with uneven spatiotemporal distribution. The average annual rainfall in the region is about $422 \mathrm{~mm}$, while the average annual evaporation is $1681 \mathrm{~mm}$, or about 4.23 times greater than the level of precipitation. The average annual transit water volume is 20.774 billion $\mathrm{m}^{3}$, and the surface water volume is sufficient. The groundwater types are divided into pore diving and pore confined water. The groundwater is shallow with slow runoff [20]. The maximum groundwater depth is $8.84 \mathrm{~m}$, the minimum is $1.54 \mathrm{~m}$ and the mean is $4.19 \mathrm{~m}$. The hydrochemical types are mainly $\mathrm{HCO}_{3}-\mathrm{Na}, \mathrm{HCO}_{3}-\mathrm{Na} \cdot \mathrm{Ca}$ and $\mathrm{HCO}_{3}-\mathrm{Na} \cdot \mathrm{Mg} \cdot \mathrm{Ca}$ [21]. Because of the diversion irrigation project, grassland degradation and cultivated land area increase obviously in this area. Irrigation water is used vertically and laterally through channels, while groundwater is replenished by infiltration and lateral infiltration after irrigation. Groundwater replenishes the soil water in the zone through the action of capillaries, after which vegetation absorbs soil water through the root system.

\section{Sampling and Testing}

Based on the land use situation of Da'an and the existing groundwater level data, 113 sampling points (Fig. 1) were uniformly arranged by global positioning system (GPS). The sampling was repeated three times, and the average value was calculated as the value of each point. Sampling was conducted in April 2018 and collected at a depth of $30 \mathrm{~cm}$, after which residual plant roots, stone particles and other impurities were removed. About $10 \mathrm{~g}$ were put into soil sample bags for numbering and recording. GPS was also 

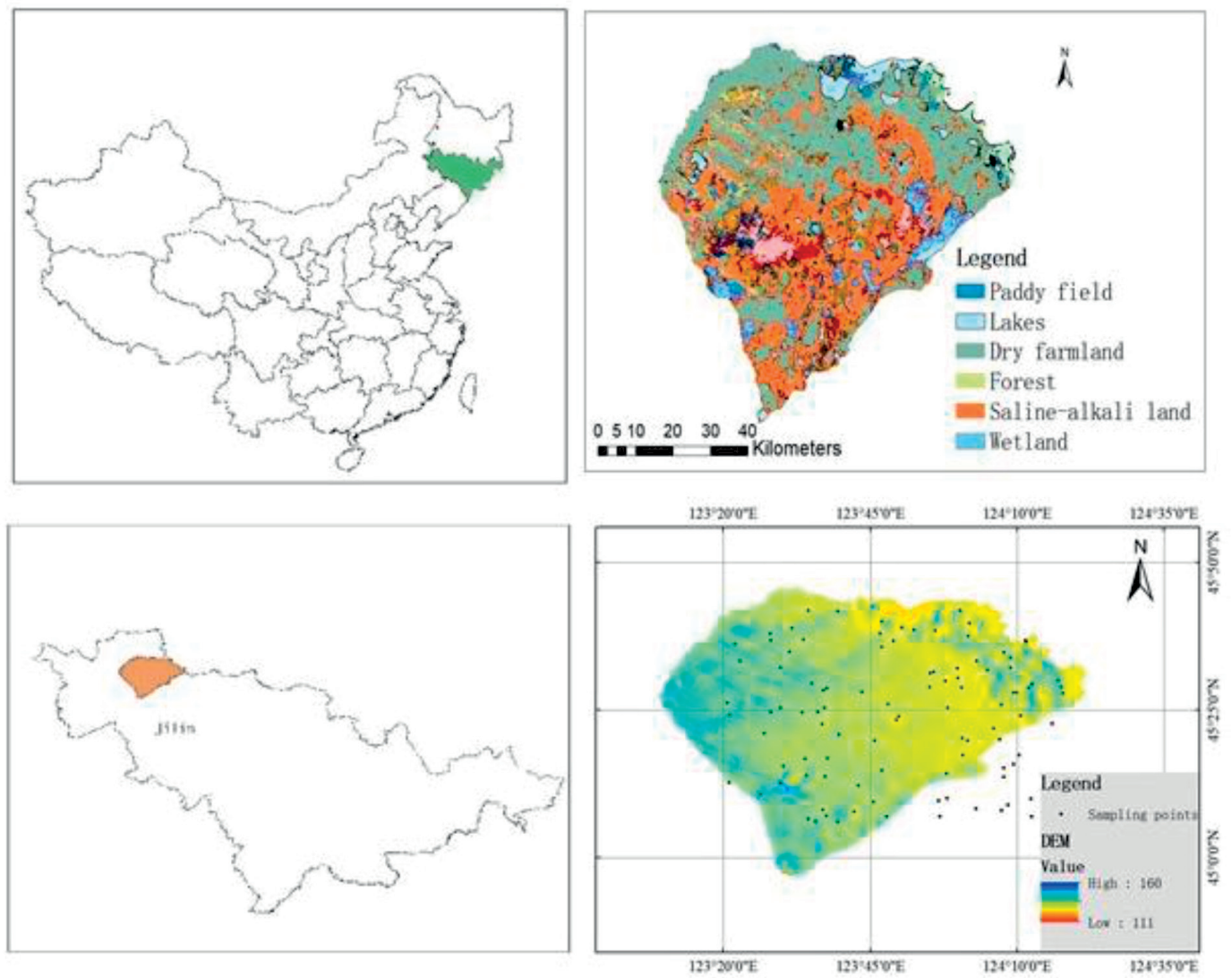

Fig. 1. Location of the study area and sampling points.

used to determine the location of the groundwater wells near the sampling points to collect water samples and depth.

Soil salinity, the ratio of the weight of soluble salinity in the soil to the weight of dry soil, was expressed as a percentage. To measure the groundwater depth, the distance between the surface of the groundwater and the ground was determined using a rope. The salinity of groundwater was determined by the gravimetric method.

\section{Topographic Variables}

A digital elevation model (DEM) with a cell size of $30 \mathrm{~m}$, was used to calculate the morphometric spatial predictors in ArcGIS 10.0 software. DEM was downloaded from the gscloud.cn website, and then pre-processed by mosaicking and filling a sink to obtain DEM files covering the study extent. Five topographic variables: slope, aspect, topographic wetness index (TWI), and roughness, amplitude of landforms (AL) were extracted.

\section{Data Analysis}

\section{Regression Kriging}

The optimal linear regression relationship between dependent variables and independent variables was established by OLS method. The trend term representing the deterministic part and the residual term representing the stochastic part are obtained. Then the normal kriging method is used to interpolate the residual and the two are added together to obtain the regression kriging interpolation result. The process can be expressed as:

$$
f(x)=m(x)+\varepsilon(x)
$$

...where $m(x)$ is the deterministic part fitted by the regression model, $\varepsilon(x)$ is the interpolated residual by ordinary Kriging (OK, a fundamental Kriging method).

Interpolated residuals by $\mathrm{OK}$ can be expressed as:

$$
\varepsilon(x)=\sum_{i=1}^{n} \lambda_{i} \times e_{i}
$$

...where $\lambda_{i}(\mathrm{i}=1 \ldots \mathrm{n})$ is the OK kriging weights and $n$ is the number of locations, with a constraint $\Sigma \lambda_{i}=1$, and $e_{i}$ is the regression residuals. The variance of regression residuals is represented by:

$$
D(e)=\gamma(h)=\frac{1}{2 n(h)} \sum_{i=1}^{n(h)}\left[e\left(x_{i}+h\right)-e\left(x_{i}\right)\right]^{2}
$$

...where $h$ is the vector of distance and $\gamma(h)$ is the semivariance function. 


\section{Geographically Weighted Regression Kriging}

GWRK replaces global fitting in RK method with local fitting in GWR. Then the local fitting residual of the interpolation points is interpolated by ordinary Kriging. The GWR model is represented as follows:

$$
Y_{G W R}\left(x_{0}\right)=\beta_{0}\left(x_{0}\right)+\sum_{i=1}^{n} \beta_{i}\left(x_{i}\right) X_{i}\left(x_{0}\right)
$$

...where $\mathrm{Y}_{G W R}\left(x_{0}\right)$ is the simulation value of the dependent variable at $x_{0} ; X_{i}\left(x_{0}\right)$ is the measurement value of the $i$ independent variable at $x_{0} ; \beta_{0}\left(x_{0}\right)$ is the coefficient of local estimation, obtained by weighted least square method, is the function of spatial position, and the gaussian function is used to estimate the weight matrix.

GWRK method is an extension and extension of GWR method. OK method is used to interpolate the residual error after fitting the local model GWR, and then it is added to the fitting trend of GWR method, and the expression is as follows:

$Y_{G W R K}\left(x_{0}\right)=\beta_{0}\left(x_{0}\right)+\sum_{i=1}^{n} \beta_{i}\left(x_{i}\right) X_{i}\left(x_{0}\right)+\varepsilon\left(x_{0}\right)$

...where $\varepsilon\left(x_{0}\right)$ is the residual of GWR model after fitting at $x_{0}$, and $\mathrm{OK}$ method is adopted for interpolation.

\section{Validation Techniques}

In order to evaluate the interpolation by $\mathrm{RK}$ and GWRK, verify the measured value and estimated value of the sampling point for accuracy evaluation. The corresponding evaluation indicators and their formulas are as follows:

$$
\begin{gathered}
M E=\frac{1}{N} \sum_{i=1}^{N}\left[Y\left(x_{i}\right)-X\left(x_{i}\right)\right] \\
M A E=\frac{1}{N} \sum_{i=1}^{N}\left[\left|Y\left(x_{i}\right)-X\left(x_{i}\right)\right|\right] \\
R M S E=\sqrt{\frac{1}{N} \sum_{i=1}^{N}\left[Y\left(x_{i}\right)-X\left(x_{i}\right)\right]^{2}} \\
R I=\frac{R_{G W R K}-R_{R K}}{R_{R K}} \times 100
\end{gathered}
$$

RI is used to compare the accuracy improvement of different interpolation methods in pairs

The ArcGIS 10.0 software was used to analyze the spatial variability of the test data. The SPSS software was used for descriptive and correlation analysis of the sample data, and Excel 2019 was used for drawing.

Table 1. Statistical characteristic of soil salinity.

\begin{tabular}{|c|c|c|c|c|c|c|c|c|}
\hline Index & Maximum & Minimum & Mean & $\begin{array}{c}\text { Standard } \\
\text { deviation }\end{array}$ & $\begin{array}{c}\text { Coefficient of } \\
\text { variation (\%) }\end{array}$ & $\begin{array}{c}\text { Coefficient } \\
\text { of skewness }\end{array}$ & $\begin{array}{c}\text { Kurtosis } \\
\text { coefficient }\end{array}$ & K-S \\
\hline $\begin{array}{c}\text { Soil salinity } \\
(\mathrm{g} / \mathrm{kg})\end{array}$ & 18.840 & 0.550 & 3.700 & 6.182 & 167.294 & 2.718 & 7.522 & 0.005 \\
\hline
\end{tabular}

Table 2. Pearson correlation matrix between Soil salinity (Soil-S) and environmental variables.

\begin{tabular}{|c|c|c|c|c|c|c|c|c|c|c|c|}
\hline Variables & Soil-S & NS & WE & Aspect & Roughness & DEM & AL & Slope & TWI & GD & GS \\
\hline Soil-S & 1 & & & & & & & & & & \\
\hline NS & -0.24 & 1 & & & & & & & & & \\
\hline WE & $-0.20^{* *}$ & -0.04 & 1 & & & & & & & & \\
\hline Aspect & -0.07 & $-0.23^{* *}$ & $0.26^{* *}$ & 1 & & & & & & & \\
\hline Roughness & 0.02 & $-0.24 * *$ & $-0.17^{* *}$ & $0.17^{* *}$ & 1 & & & & & & \\
\hline DEM & $-0.04^{*}$ & $-0.33^{* *}$ & $-0.24^{* *}$ & $0.15^{* *}$ & $0.42^{* *}$ & 1 & & & & & \\
\hline AL & 0.03 & $-0.24^{* *}$ & $-0.32^{* *}$ & 0.08 & $0.85^{* *}$ & $0.53^{* *}$ & 1 & & & & \\
\hline Slope & -0.01 & $-0.11^{*}$ & $-0.18^{* *}$ & $0.12^{*}$ & $0.65^{* *}$ & $0.21 * *$ & $0.47^{* *}$ & 1 & & & \\
\hline TWI & $0.21 * *$ & 0.02 & $0-.04$ & $-0.14^{*}$ & $-0.29^{* *}$ & -0.07 & $-0.17^{* *}$ & $-0.29 * *$ & 1 & & \\
\hline GD & 0.09 & $-0.21^{* *}$ & $-0.22^{* *}$ & $-0.16^{* *}$ & 0.04 & $0.39^{* *}$ & $0.15^{* *}$ & $-0.12^{*}$ & -0.04 & 1 & \\
\hline GS & $-0.26^{* *}$ & $0.63^{* *}$ & $0.24^{* *}$ & 0.02 & $-0.24^{* *}$ & $-0.35^{* *}$ & $-0.20^{* *}$ & $-0.15^{* *}$ & 0.02 & $-0.44^{* *}$ & 1 \\
\hline
\end{tabular}

** correlation is significant at the 0.01 level (two-tailed); * correlation is significant at the 0.05 level (two-tailed) 


\section{Results and Discussion}

\section{Statistical Analysis of Soil Salinity}

The results of statistical parameters are shown in Table 1.

Soil salinity mean is $3.7 \mathrm{gg} / \mathrm{kg}$, ranged from 0.55 to $18.84 \mathrm{~g} / \mathrm{kg}$, and standard deviation is 6.182 . The variation coefficient of $167.294 \%(>100 \%)$ was strong variation. Evaluation of the skewness and kurtosis revealed that the skewness of soil salinity was larger and that there was significant positive skewness. Evaluation of statistical distribution of soil salinity was tested by k-s test revealed that at the test level of 0.05 , it was normally distributed. The findings presented above indicated that the variability of soil salinity was significantly greater, possibly because of the complex factors affecting the distribution of salinity. Therefore, it is necessary to analyze the correlation of soil salinity and environmental factors.

\section{Correlation Analysis of Soil Salinity and Environmental Factors}

Correlations between the soil salinity (Soil-S) and the auxiliary variables, including DEM, Slope, Aspect, Roughness, Amplitude of landforms(AL), Topographic Wetness Index (TWI), Groundwater depth (GD), Groundwater salinity (GS), Longitude(WE) and Latitude(NS), these variables of aspect were tested by Pearson correlation analysis (Table 2).

Soil salinity has a significant negative correlation with latitude and DEM, and a very significant positive correlation with TWI and groundwater salinity. Based on the relationship between the above four environmental factors and soil salinity, it can be preliminarily inferred that areas with low topography, high groundwater salinity and high soil moisture are conducive to the accumulation of soil salinity. The four environmental variables were used for stepwise regression analysis.

\section{Spatial Characteristics of Soil Salinity with RK and GWRK Models}

\section{Evaluation and Process of Regression}

Stepwise regression can not only ensure that the auto variables significantly related to soil salinity enter the regression model, but also remove collinearity between the independent variables. Based on the results of stepwise regression, the linear regression equation used in this study is expressed as in Equation (10). The significance of OLS regression parameters is given in Table 3.

$$
\begin{aligned}
& \text { Soil salinity }=25.739-0.005 G S \\
& +11.418 \times T W I-0.117 \times D E M
\end{aligned}
$$

DEM, Groundwater salinity and TWI are the best independent variables for interpolation of soil salinity (Table 3). The $\mathrm{P}$ values of the predicted values of all variables were less than 0.05 , and the VIF values were less than 10 , so there was no multicollinearity. The model determination coefficient (Adjusted $\mathrm{R}^{2}$ ) is about 0.40 , which can meet the basic requirements of the statistical model to a certain extent.

Geographically weighted regression was also implemented using the selected predictor as same as OLS. The optimal bandwidth is $8.15 \mathrm{~km}$ in this study when the Gaussian is used. The statistics of regression coefficients of variables in the GWR model are shown in Table 4 and is expressed as in Equation (11). The GWR determination coefficient (Adjusted $\mathrm{R}^{2}$ ) is 0.418 .

$$
\begin{aligned}
& \text { Soil salinity }=29.164-0.005 \mathrm{GS} \\
& +12.908 \times \mathrm{TWI}-0.145 \times \mathrm{DEM}
\end{aligned}
$$

\section{Regression Residuals Interpolation}

\begin{tabular}{|c|c|c|c|c|c|c|}
\hline \multirow{2}{*}{ Model } & \multirow{2}{*}{ Variable } & Unstandardized coefficient & Unstandardized coefficient & \multirow{2}{*}{$\begin{array}{l}\text { Adjusted R } \\
\text { square }\end{array}$} & \multirow{2}{*}{ VIF } & \multirow{2}{*}{$\mathrm{p}$} \\
\hline & & $\mathrm{B}$ & Beta & & & \\
\hline \multirow{2}{*}{1} & Constant & 10.239 & & \multirow{2}{*}{0.476} & \multirow{2}{*}{1.000} & \multirow{2}{*}{0.000} \\
\hline & GS & -0.004 & -0.269 & & & \\
\hline \multirow{3}{*}{2} & Constant & 9.453 & & \multirow{3}{*}{0.430} & \multirow{3}{*}{$\begin{array}{l}1.001 \\
1.001\end{array}$} & \multirow{3}{*}{0.000} \\
\hline & GS & -0.004 & -0.274 & & & \\
\hline & TWI & 11.919 & 0.224 & & & \\
\hline \multirow{4}{*}{3} & Constant & 25.739 & & \multirow{4}{*}{0.400} & & \multirow{4}{*}{0.009} \\
\hline & GS & -0.005 & -0.324 & & 1.141 & \\
\hline & TWI & 11.418 & 0.214 & & 1.005 & \\
\hline & DEM & -0.117 & -0.143 & & 1.147 & \\
\hline
\end{tabular}

Descriptive statistics show that the residual values after OLS fitting range from -2.48 to $3.51 \mathrm{~g} / \mathrm{kg}$, kurtosis

Table 3. Stepwise process of the multiple linear regression analysis of soil salinity. 
Table 4. Stepwise process of GWR of soil salinity.

\begin{tabular}{|c|c|c|c|c|}
\hline \multirow{2}{*}{ Variable } & Unstandardized coefficient & Unstandardized coefficient & \multirow{2}{*}{ Adjusted R square } & P \\
\cline { 2 - 3 } & B & Beta & & .000 \\
\hline Constant & 29.164 & & & .000 \\
\hline DEM & -0.145 & -0.273 & 0.418 & .000 \\
\hline GS & -0.005 & -0.415 & & .000 \\
\hline TWI & 12.098 & 0.711 & & .000 \\
\hline
\end{tabular}

Table 5. Descriptive statistic of OLS residuals and GWR residuals.

\begin{tabular}{|c|c|c|c|c|c|}
\hline Variable & MIN. & MAX. & MEAN & Skewness & Kurtosis \\
\hline OLS residuals & -2.48 & 3.51 & 0.437 & 0.048 & -0.886 \\
\hline GWR residuals & -1.49 & 2.53 & 0.837 & 0.394 & 0.868 \\
\hline
\end{tabular}

is -0.886 , skewness is 0.048 . GWR residual values range from -1.49 to $2.53 \mathrm{~g} / \mathrm{kg}$, kurtosis is -0.394 , skewness is 0.868 . Both have passed the $\mathrm{k}-\mathrm{s}$ test and are suitable for geostatistical interpolation (Fig. 2). The semi-variance analysis of OLS and GWR residual is calculated (Fig. 3 and Table 6).

Nugget $\left(\mathrm{C}_{0}\right)$ reflects the degree of spatial variation caused by random factors of regionalized variables. The ratio of nugget and sill in the variogram model
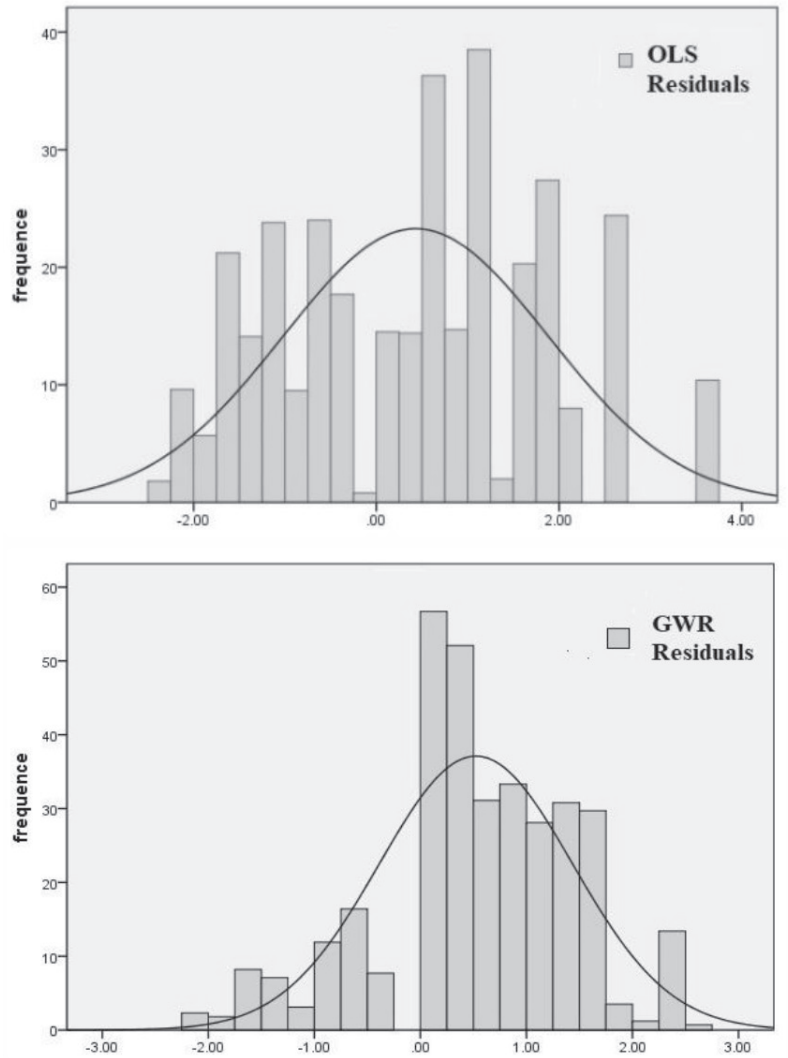

Fig. 2. Histogram of the soil salinity residuals from OLS and GWR regression.
$\left(\mathrm{C}_{0} /\left(\mathrm{C}_{0}+\mathrm{C}\right)\right)$, represents the spatial dependence structure, which can be explained as the proportion of spatial heterogeneity caused by random factors. When the ratio is less than $25 \%$, regression residuals are spatially dependent. If the ratios is $25 \%-75 \%$, residuals have a moderately strong spatially dependent structure. Until the ratio reaches above $75 \%$, the spatial

a) e: Isotropic V ariogram

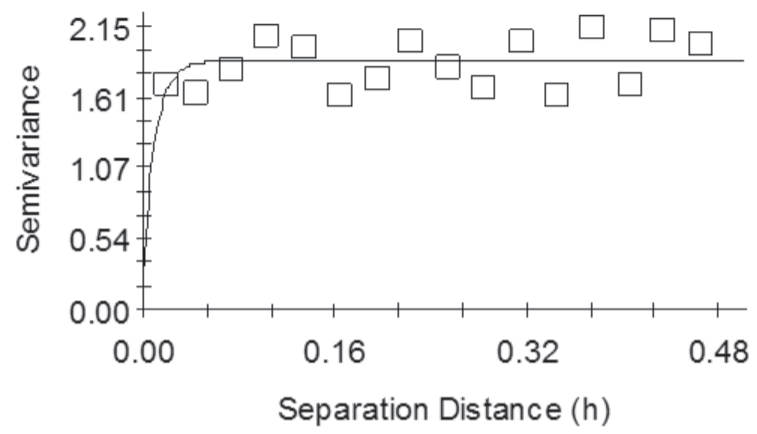

b)

e: sotropic Variogram

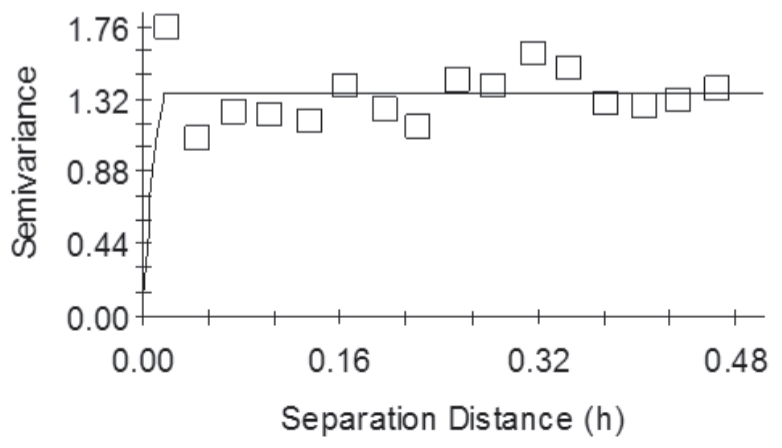

Fig. 3. Residual variograms and models fitted for RK a) and GWRK b). 
Table 6. The semi-variation function parameters of OLS and GWR regression residuals.

\begin{tabular}{|c|c|c|c|c|c|c|}
\hline ITEM & $\begin{array}{c}\text { Theoretical } \\
\text { model }\end{array}$ & $\begin{array}{c}\text { Nugget } \\
\mathrm{C}_{0}\end{array}$ & $\begin{array}{c}\text { Sill } \\
\mathrm{C}_{0}+\mathrm{C}\end{array}$ & $\begin{array}{c}\text { Proportion (\%) } \\
\mathrm{C}_{0} /\left(\mathrm{C}_{0}+\mathrm{C}\right)\end{array}$ & Range & $\mathrm{R}^{2}$ \\
\hline OLS & Exponential & 0.20 & 1.88 & 10.6 & 0.03 & 0.706 \\
\hline GWR & Exponential & 0.092 & 1.35 & 6.8 & 0.019 & 0.710 \\
\hline
\end{tabular}

dependence structure is very weak. In this study, the nugget of OLS and GWR residuals is less than 1, which shows that the spatial variability was predominately caused by structural factors. The random factors of soil variation have little influence, and the variation is mainly controlled by structural factors. This also indirectly confirms the feasibility of applying terrain factors to assist interpolation. The $\mathrm{C}_{0} /\left(\mathrm{C}_{0}+\mathrm{C}\right)$ of OLS residuals was $10.6 \%$, and GWR residuals of $6.8 \%$ signifies that spatial variability caused by random factors in OLS residuals was greater than in GWR residuals. These different degrees of spatial dependence structure in the two regression residuals could be induced by different degrees of trend elimination in residuals of the two regression models. The coefficient of determination is above $70 \%$, and good fitting results are obtained.

\section{Performance of RK and GWRK Model}

Based on the above analysis, the soil salinity, OLS residual values and GWR residual values of were interpolated by ordinary Kriging (OK), and the spatial distribution of soil salinity was obtained by RK and GWRK (Fig. 4). The variation range of soil salinity obtained by RK method was $0.166 \sim 12.99 \mathrm{~g} / \mathrm{kg}$. From east to west, the distribution of soil salinity showed an overall trend, which is "low on both sides and high in the middle". The high value appeared in the areas with more lakes, which may be related to the drainage of irrigation and salinity discharge in the study area. In addition,

a)

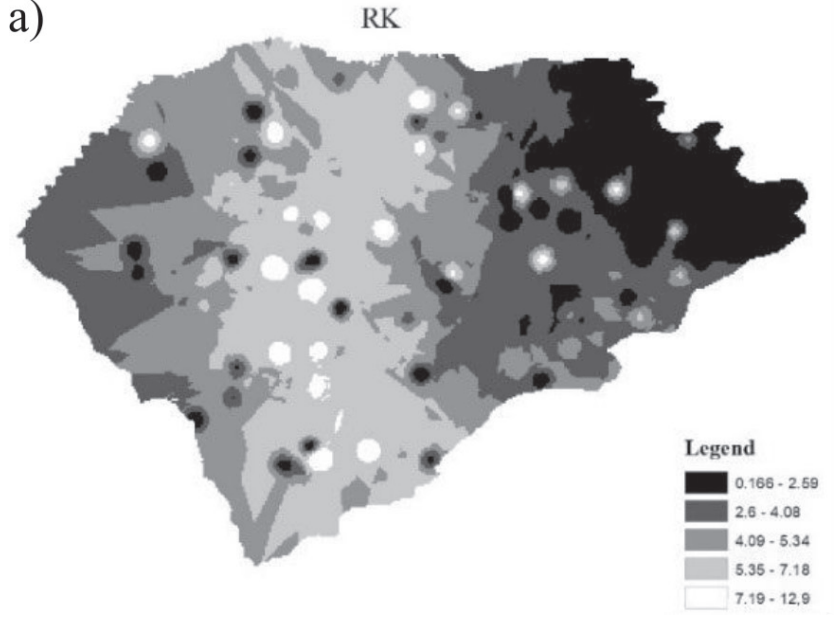

because of the strong evaporation, the capillary water in the aerated zone raised, bringing the soluble salinity in the groundwater to the soil surface. This phenomenon is reasonable. The variation range of soil salinity obtained by GWRK method was $0.357 \sim 11.6 \mathrm{~g} / \mathrm{kg}$, and the overall distribution was basically consistent with RK method. The range of salinity predicted by $\mathrm{RK}$ is wider than the range predicted by GWRK (Fig. 4). The salinity distributions predicted by RK showed more spatial variation than those predicted by GWRK. According to the five evaluation indexes of MA, MAE, RMSE, R and RI (Table 7), RK method and GWRK method with terrain factor as auxiliary variable have higher accuracy indexes, while the GWRK accuracy is improved by $23.2 \%$. GWRK method is better than RK method in simulating the spatial distribution of soil salinity.

\section{Relationship of Groundwater on Soil Salinization}

Studies have shown that groundwater salinity is an important source of soil salinity, and there is a significant correlation between groundwater salinity and soil salinity [22] (Table 2). After obtaining the spatial distribution of soil salinity, it is generally combined with groundwater to regulate soil salinity, because it is necessary to understand the relationship between groundwater and soil salinity. To quantitatively analyze the relationship among these three factors, data from the measured soil salinity, groundwater depth and groundwater salinity test data of all sample points were integrated for unified analysis.

b)

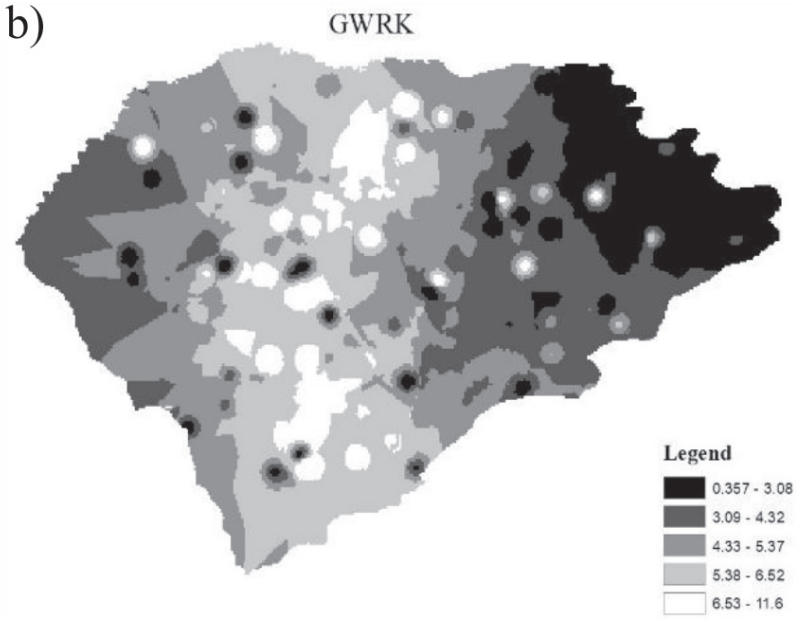

Fig. 4 Soil salinity map predicted by RK a) and GWRK b). 
Table 7. Validation of RK and GWRK models.

\begin{tabular}{|c|c|c|c|c|c|}
\hline METHOD & ME & MAE & RMSE & R & RI (\%) \\
\hline RK & -1.911 & 3.226 & 4.001 & 0.702 & \\
\hline GWRK & -1.462 & 2.929 & 3.946 & 0.864 & 23.2 \\
\hline
\end{tabular}

To further quantitatively analyze the relationship of soil salinity on groundwater depth and groundwater salinity, assuming that one variable was unchanged first. Based on the data measured at the sampling sites and the quality standard for groundwater (GB/T148482007), data were divided into two groups ( $>1 \mathrm{~g} / \mathrm{L}$ and $<1 \mathrm{~g} / \mathrm{L})$ to analyze the relationship between soil salinity and groundwater depth. Fitting the test data of sampling points with different groundwater salinities revealed a functional relationship (Fig. 5).

Through the sampling points of different groundwater salinity test data fitting, it has a certain functional relation, respectively:

$$
\begin{aligned}
& y=6.5133 x^{-2.744} \\
& y=0.7636 x^{-1.686}
\end{aligned}
$$
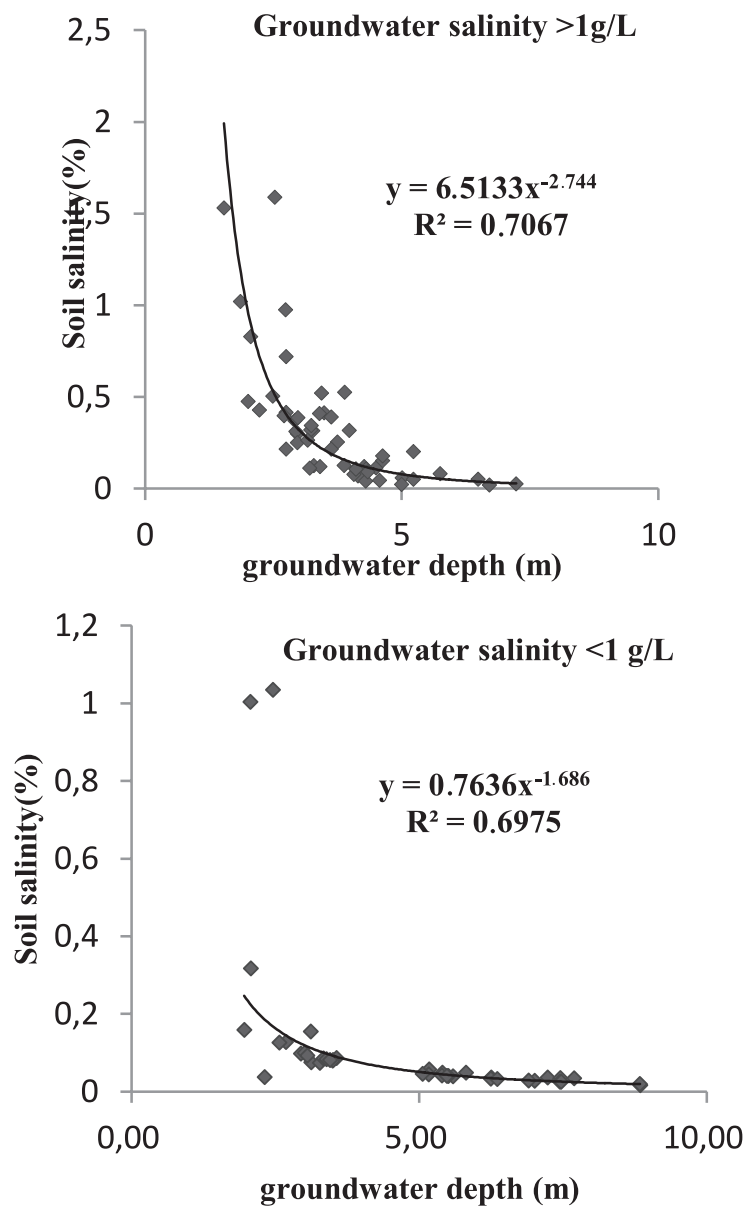

Fig. 5. Fitting diagram of the relationship between soil salinity and groundwater depth. ...where, $\mathrm{y}$ represents the soil salinity and $\mathrm{x}$ represents the groundwater depth.

After the local groundwater depth increased to a certain level, the soil salinity tended to remain at a constant value (Fig.5 ). When the groundwater salinity $<1 \mathrm{~g} / \mathrm{L}$, the groundwater depth less than $5 \mathrm{~m}$, soil salinity decreased significantly with increasing groundwater depth, indicating that shallow groundwater was an important cause of salinity generation and accumulation. The Equation (12-13) generated was a power function with a negative exponent, and the correlation coefficient was around 0.7. In the case of similar groundwater salinity, shallower groundwater with less than $5 \mathrm{~m}$ was associated with more salinity and accumulation.

Based on previous analysis, the soil salinity changed greatly before reaching $5 \mathrm{~m}$; therefore, the groundwater depth was divided into two groups ( $>5 \mathrm{~m}$ and $<5 \mathrm{~m}$ ),
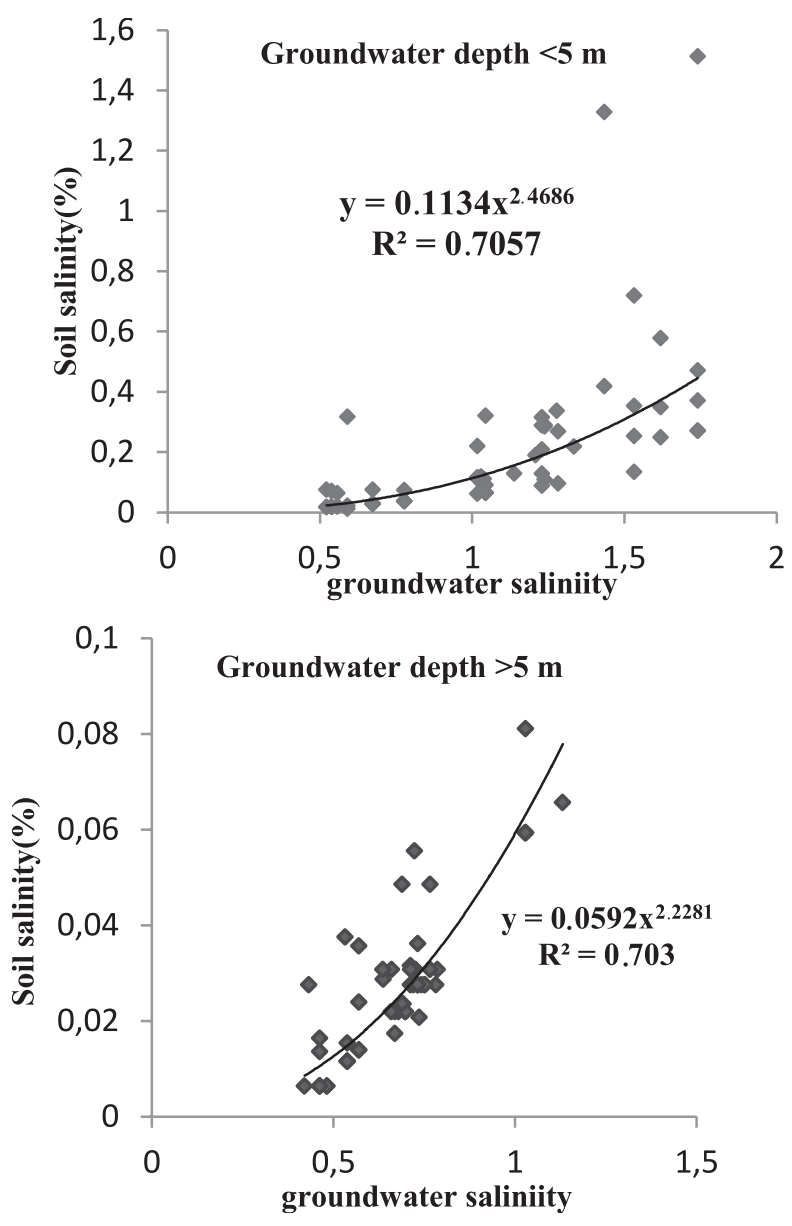

Fig. 6. Fitting diagram of the relationship between soil salinity and groundwater salinity. 
after which the data from each group were analyzed separately (Fig. 6).

Through the sampling points of different groundwater salinity data fitting, it has a certain functional relation, respectively:

$$
\begin{aligned}
& y=0.1134 x^{2.4686} \\
& y=0.0592 x^{2.2281}
\end{aligned}
$$

...where, $y$ represents the soil salinity and $x$ represents the groundwater salinity.

When the groundwater depth was similar, the soil salinity increased with increasing groundwater salinity (Fig. 6). According to the Equation (14-15), the correlation coefficient is around 0.7 , and the fitting precision is good.

The relatively low correlation coefficient may have occurred because the soil texture conditions were not very different, and natural conditions such as topography, geomorphology, microclimate, hydrology, as well as the complicated process of sample selection and sampling, and some human factors are involved in the interference. However, relevant data have shown that there is an exponential relationship between soil salinity and groundwater salinity in Xinjiang irrigation areas, northwest China [23]. In the area investigated for the present study, we found that there was a good power exponent function relationship between groundwater salinity and soil salinity.

Generally, existing studies only use an index of groundwater depth or groundwater salinity separately to fit the function with soil salinity [24], which brings inconvenience to the analysis of soil salinity under different groundwater environments. The relationship among soil salinity, groundwater depth and groundwater salinity can be determined through the equation. Therefore, all data were further analyzed, and all the conditions were repeatedly calculated and integrated to achieve this goal with minimum error.
Evaluation of the Equation (12-15) revealed that they all showed a good power function can be summarized as follows:

$$
y=a x^{b}
$$

...where, $y$ represents the soil salinity and $x$ represents the groundwater depth or groundwater salinity. Therefore, the three factors have the relationship depicted in Fig. 7.

The result is shown in Equation (17).

$$
z=0.8402\left(\frac{x}{y}\right)^{-1.429}
$$

...where, $z$ represents the soil salinity, $x$ represents the groundwater depth, and $y$ represents groundwater salinity.

Specifically it can express the relationship curve between soil salinity, groundwater depth and salinity. The correlation coefficient can reach $>0.7$ (Fig. 7). These results showed that the multiple power function can describe the relationship between soil salinity, groundwater depth and groundwater salinity well. Therefore, the relationship can be directly used to predict soil salinity in this study area, while also providing an example for research in similar areas.

\section{Discussion}

The spatial variation of soil properties is controlled by various structural and random factors [25]. Topographic factors, i.e. slope, aspect, roughness, etc., can regulate the redistribution of water, heat and matter. Therefore, it affects the degree and intensity of soil variation, and is the structural factor that has the strongest effect on soil variation under natural conditions. In this study, combining the characteristics of the study area, terrain factors such as DEM, TWI and groundwater salinity were selected as auxiliary

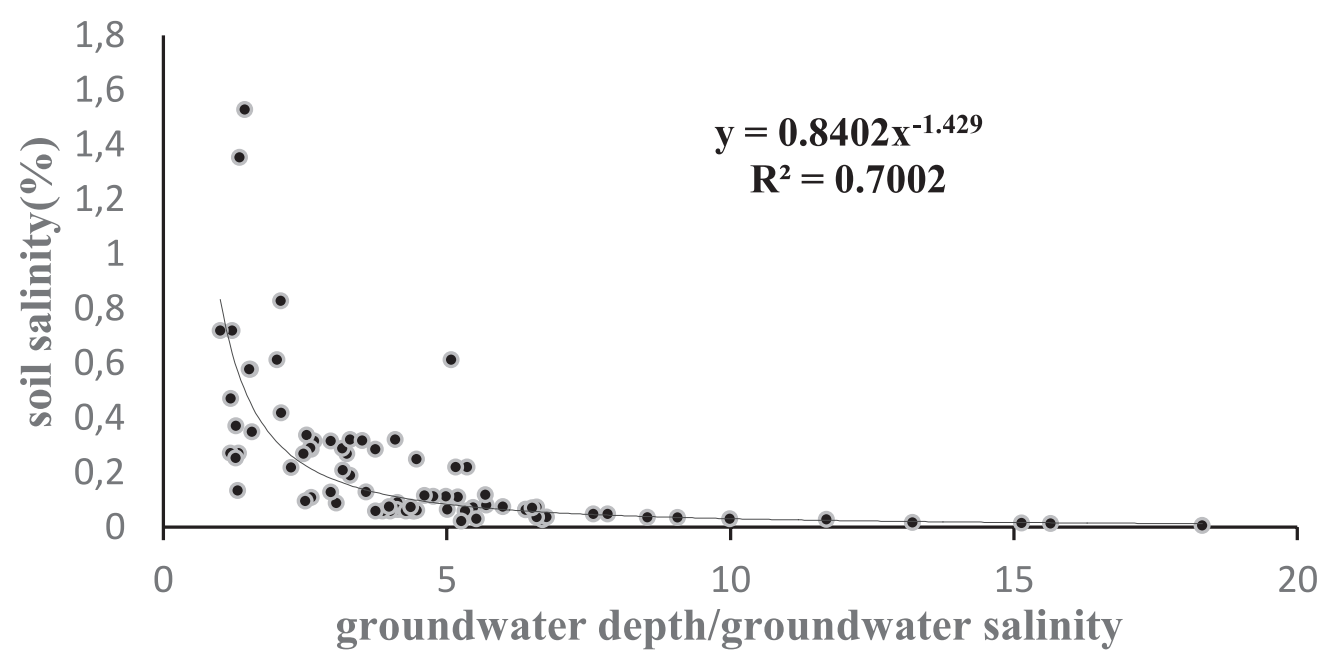

Fig. 7. Relationship between soil salinity, groundwater depth and groundwater salinity. 
variables to be included in the RK and GWRK interpolation model, and to improve the accuracy of soil salinity interpolation were discussed.

The RK can not only use the relationship between variables and terrain factors to establish a global regression model, but also make full use of sample information for ordinary Kriging interpolation in the presence of spatial autocorrelation of residuals [26]. But it does not take into account the effect of spatial heterogeneity on model fitting, which has certain limitations. The GWR relies on changes in the weight function to capture local spatial information, eliminating the effect of spatial heterogeneity on model fitting, and improving the model's estimation and prediction capabilities. The GWRK extends the GWR. It takes into account both the impact of spatial heterogeneity on model estimation and the spatial correlation structure inherent to the residuals of the GWR model to improve accuracy. Scholars use GWRK to make spatial prediction and mapping of soil properties. They proved its superiority in improving interpolation accuracy and capturing spatial non-stationarity [27-29]. This study used the GWRK model to estimate soil salinity, and its prediction accuracy was consistent with the results of the above-mentioned scholars. This is a useful attempt the five accuracy indicators of the model showed better than RK. The value of GWRK in individual areas is more abundant. However, with an increase in the size of the study area and the complexity of the underlying surface, the relationship between soil and auxiliary variables will become more unstable. When selecting topographic factors in this paper, some factors have not been quantified and taken into account, such as land use changes such as upland fields and paddy fields. In addition, the sampling points need to be enriched to improve the accuracy of the results. The drainage direction of the irrigation is natural lakes in study area. Due to the high temperature, little rainfall, and strong evaporation in summer, soluble salinity in deep soil and groundwater are accumulated in the topsoil by the rise of capillary water in the aerated zone, thereby forming a high-salinity partition, strong variability, consistent with the results of combining GWRK. Groundwater is closely related to soil salinity. From the correlation between soil salinity and environmental factors (Table 2), it can be seen that there is a correlation between groundwater depth and salinity, and there is a very significant positive correlation with salinity. How to control groundwater to control soil salinization is a difficult problem, and crops, climate, soil texture, and human factors need to be considered at the same time. This study preliminarily concludes that the three can be expressed by a multivariate power function, which can provide managers with a preliminary judgment based on less other environmental information. However, the experimental data is still lacking a long series of observations, and it is necessary to continue to improve and improve the accuracy of the empirical equation.

\section{Conclusions}

This article takes the saline soil area of western Jilin as the research area, and uses the RK and GWRK to study the spatial distribution of soil salinity. Through correlation analysis and collinearity test, the optimal auxiliary factors selected were DEM, TWI and groundwater salinity, which all reached extremely significant correlations. The RK and GWRK can effectively predict the spatial distribution of soil salinity, and the GWRK accuracy is improved by $23.2 \%$, which overcomes spatial non-stationarity. The mapping effect has been improved, and the information of the image in a small area is more abundant. The high value of soil salinity appeared in the areas with more lakes, because of the strong evaporation, the capillary water in the aerated zone raised, bringing the soluble salinity in the groundwater to the soil surface. According to qualitative relationship of soil salinity, groundwater depth and groundwater salinity, when groundwater depth was generally less than $5 \mathrm{~m}$, soil salinity increases as groundwater depth decreases, then tends to reach a constant value at depths greater than $5 \mathrm{~m}$ with the similar groundwater salinity. On this basis, multiple power functions were used to quantitatively express the relationship. In this study, soil salinity can be predicted and controlled through groundwater to provide a scientific basis for the management of soil salinity in salinized areas. At the same time, more questions about improving the spatial interpolation accuracy of soil salinity and the quantitative relationship between soil salinity and groundwater should be further developed.

\section{Acknowledgements}

Scientific Research Foundation of Changchun Institute of Technology Jilin Province, China (Grant No. 01130292019011) and "Thirteenth Five-Year Plan" Science and Technology Project of Education Department of Jilin Province (JJKH20191266KJ) for financially supporting this research. The authors also appreciate the anonymous reviewers and editors for their contributions and help to this research.

\section{Conflict of Interest}

The authors declare no conflict of interest.

\section{References}

1. KOROLYUK V.T. Soil forming factors: Their role in the formation of saline soils on the plains of Western and Central Ciscaucasia. Eurasian Soil Science, 48 (7), 689, 2015.

2. YAO R., YANG J. Quantitative evaluation of soil salinity and its spatial distribution using electromagnetic induction method. Agr. Water. Manage., 97 (12), 0-1970, 2010. 
3. MA J., YANG S., SHI H., DING X., HAN W. Irrigation schedule for maize based on soil moisture and salt content threshold in Hetao irrigation district. Transactions of the Chinese Society of Agricultural Engineering (In Chinese), 30 (11), 83, 2014.

4. ZEWDU S., SURYABHAGAVAN K.V., BALAKRISHNAN M. Geo-spatial approach for soil salinity mapping in Sego Irrigation Farm, South Ethiopia. Journal of the Saudi Society of Agricultural Sciences, 16 (1), 16, 2017.

5. LI J., HEAP A.D. Spatial interpolation methods applied in the environmental sciences: A review. Environ.Modell. Softw., 53, 173, 2014.

6. SEO Y., KIM S., SINGH V.P. Estimating Spatial Precipitation Using Regression Kriging and Artificial Neural Network Residual Kriging (RKNNRK) Hybrid Approach. Water Resour. Manage., 29 (7), 2189, 2015.

7. YE H., HUANG W., HUANG S., HUANG Y., ZHANG S., DONG Y., CHEN P. Effects of different sampling densities on geographically weighted regression kriging for predicting soil organic carbon. Spatial Statistics, 20, 76, 2017.

8. BILGILI A.V. Spatial assessment of soil salinity in the Harran Plain using multiple kriging techniques. Environmental Monitoring and Assessment, 185 (1), 777, 2013.

9. JIN Q.T., ZHANG J.T., SHI M.C., HUANG J.X. Estimating Loess Plateau Average Annual Precipitation with Multiple Linear Regression Kriging and Geographically Weighted Regression Kriging. Water, 8 (6), 266, 2016.

10. SONG X.D., BRUS D.J., LIU F., LI D.C., ZHANG G.L. Mapping soil organic carbon content by geographically weighted regression: A case study in the Heihe River Basin, China. Geoderma, 261, 11, 2016.

11. KUMAR S., LAL R., LIU D. A geographically weighted regression kriging approach for mapping soil organic carbon stock. Geoderma, 189-190, 627, 2012.

12. LI X., SHANG B., WANG D., WANG Z., WEN X., KANG Y. Mapping soil organic carbon and total nitrogen in croplands of the Corn Belt of Northeast China based on geographically weighted regression kriging model. Computers \& Geosciences, 135, 104392, 2020.

13. YANG S.-H., LIU F., SONG X.-D., LU Y.-Y., LI D.-C., ZHAO Y.-G., ZHANG G.-L. Mapping topsoil electrical conductivity by a mixed geographically weighted regression kriging: A case study in the Heihe River Basin, northwest China. Ecological Indicators, 102, 252, 2019.

14. YANG Y., SHUWEN Z., DONGYAN W., JIUCHUN Y., XIAOSHI X. Spatiotemporal Changes of Farming-Pastoral Ecotone in Northern China, 1954-2005: A Case Study in Zhenlai County, Jilin Province. Sustainability- Basel., 7 (1), 1, 2014.

15. THOMAS M., FITZPATRICK R.W., HEINSON G.S. Spatial and temporal trends in soil salinity for identifying perched and deep groundwater systems. Soil Use Manage., 27 (2), 264, 2011.

16. DONG W.H., WEN C.L., ZHANG P., SU X.S., YANG F.T. Soil Water and Salt Transport and its Influence on Groundwater Quality: A Case Study in the Kongque River Region of China. Pol. J. Environ. Stud., 28 (3), 1637, 2019.
17. LI P., WU J., QIAN H. Regulation of secondary soil salinization in semi-arid regions: a simulation research in the Nanshantaizi area along the Silk Road, northwest China. Environ. Earth Sci., 75 (8), 698, 2016.

18. LIU G., LI, JINBIAO, ZHANG, XUECHEN, WANG X., LV Z., YANG J., SHAO H., YU S. GIS-mapping spatial distribution of soil salinity for Eco-restoring the Yellow River Delta in combination with Electromagnetic Induction. Ecol. Eng., 94, 306, 2016.

19. WANG H.W.H., LIU G.L.G. Geostatistical Analysis on Multi-Scale Variations of Soil Salinity in the Yellow River Delta[C]. International Conference on Bioinformatics \& Biomedical Engineering. IEEE, 2008.

20. NIE S., BIAN J., WAN H., SUN X., ZHANG B. Simulation and uncertainty analysis for groundwater levels using radial basis function neural network and support vector machine models. J. Water Supply Res. T., 66 (1), 15, 2017.

21. BIAN J., LIU C., ZHANG Z., WANG R., GAO Y. HydroGeochemical Characteristics and Health Risk Evaluation of Nitrate in Groundwater. Pol. J. Environ. Stud., 25 (2), $521,2016$.

22. BERN C.R., BOEHLKE A.R., ENGLE M.A., GEBOY N.J., SCHROEDER K.T., ZUPANCIC J.W. Shallow groundwater and soil chemistry response to 3 years of subsurface drip irrigation using coalbed-methaneproduced water. Hydrogeol. J., 21 (8), 1803, 2013.

23. BAOSHAN D., WAHAPU·HALIKE, JIANHUA D. Coupled analysis of spatio-temporal variability of groundwater depth and soil salinity in Keriya Oasis. Transactions of the Chinese Arid Land Geography, 38 (03), 599, 2015 [In Chinese].

24. SEEBOONRUANG U. Relationship between groundwater properties and soil salinity at the Lower Nam Kam River Basin in Thailand. Environ. Earth Sci., 69 (6), 1803, 2013.

25. LI S., LI Q.-Q., WANG C.-Q., LI B., GAO X.-S., LI Y.D., WU D.-Y. Spatial variability of soil bulk density and its controlling factors in an agricultural intensive area of Chengdu Plain, Southwest China. Journal of Integrative Agriculture, 18 (2), 290, 2019.

26. LI X., SHANG B., WANG D., WANG Z., WEN X., KANG Y. Mapping soil organic carbon and total nitrogen in croplands of the Corn Belt of Northeast China based on geographically weighted regression kriging model. Comput. Geosci-UK., 135, 104392, 2020.

27. LIANG W., FEI D., ZHONG X., SHENG H., SHU S., JUNMING S., DAN L. Spatial Analysis of Severe Fever with Thrombocytopenia Syndrome Virus in China Using a Geographically Weighted Logistic Regression Model. Int. J. Env. Res. Pub. He., 13 (11), 1125, 2016.

28. KUMAR, SANDEEP. Estimating spatial distribution of soil organic carbon for the Midwestern United States using historical database. Chemosphere, 127, 49, 2015.

29. SONG P., HUANG J., MANSARAY L.R. An improved surface soil moisture downscaling approach over cloudy areas based on geographically weighted regression. Agr. Forest. Meteorol., 275, 146, 2019. 
